University of Wollongong

Research Online

Faculty of Engineering - Papers (Archive)

Faculty of Engineering and Information

Sciences

$1-1-2010$

\title{
Direct scattered growth of MWNT on Si for high performance anode material in Li-ion batteries
}

\author{
Pengfei Gao \\ Shanghai Jiao Tong University \\ Yanna Nuli \\ University of Wollongong, yanna@uow.edu.au \\ Yu-Shi He \\ Shanghai Jiao Tong University \\ Andrew I. Minett \\ The University Of Sydney, aminett@uow.edu.au \\ Jiazhao Wang \\ University of Wollongong, jiazhao@uow.edu.au
}

See next page for additional authors

Follow this and additional works at: https://ro.uow.edu.au/engpapers

Part of the Engineering Commons

https://ro.uow.edu.au/engpapers/3570

\section{Recommended Citation}

Gao, Pengfei; Nuli, Yanna; He, Yu-Shi; Minett, Andrew I.; Wang, Jiazhao; Yang, Jun; and Chen, Jun: Direct scattered growth of MWNT on Si for high performance anode material in Li-ion batteries 2010, 9149-9151.

https://ro.uow.edu.au/engpapers/3570

Research Online is the open access institutional repository for the University of Wollongong. For further information contact the UOW Library: research-pubs@uow.edu.au 
Authors

Pengfei Gao, Yanna Nuli, Yu-Shi He, Andrew I. Minett, Jiazhao Wang, Jun Yang, and Jun Chen 


\title{
Direct scattered growth of MWNT on Si for high performance anode material in Li-ion batteries $\dagger$
}

\author{
Pengfei Gao, ${ }^{a}$ Yanna Nuli, ${ }^{a}$ Yu-Shi He,${ }^{a}$ Jiazhao Wang, ${ }^{c}$ Andrew I. Minett, ${ }^{b}$ Jun Yang ${ }^{* a}$ \\ and Jun Chen $* b$
}

Received 28th July 2010, Accepted 8th October 2010

DOI: $10.1039 / \mathrm{c0cc02870c}$

\begin{abstract}
A novel Si-MWNT nanocomposite synthesized via a CVD process shows a high reversible capacity of over $1500 \mathrm{mAh} \mathrm{g}^{-1}$ and stable cycling performance, which can be ascribed to the maintenance of a good conductive network by means of the direct scattered growth and pinning of MWNTs on Si particles.
\end{abstract}

The increase of energy density is a key point for extending the application range of lithium-ion batteries, especially for electric/hybrid vehicles. Silicon is one of the most attractive anode materials for lithium batteries on account of its low discharge potential and the well-known highest theoretical capacity of about $4200 \mathrm{mAh} \mathrm{g} \mathrm{g}^{-1}$ corresponding to the fully lithiated composition of $\mathrm{Li}_{4.4} \mathrm{Si}^{1}{ }^{1}$ which is more than ten times higher than that of commercial graphite anodes $\left(372 \mathrm{mAh} \mathrm{g}^{-1}\right){ }^{2}$ However, silicon-based electrodes suffer from very poor cyclability due to loss of electronic contact between the active particles resulting from silicon's volume changes by $400 \%$ upon insertion and extraction of lithium. ${ }^{3}$ Research results have confirmed that the decrease of particle size of the Li-storage hosts can significantly improve the electrochemical cycling behavior due to the reduced absolute volume change and weaker pulverization tendency. ${ }^{4-6}$

In order to improve the electrode stability, nano-size silicon is homogeneously dispersed within a suitable matrix resulting in a nanocomposite, in which the second phase component acts as a buffering matrix to accommodate the large volume changes upon cycling. Among the different matrix materials considered, carbon is a good candidate due to its relatively low mass, good electronic and ionic conductivity, reasonable Li-insertion capability, small volume expansion, softness and compliance. ${ }^{7}$ Various methods have been employed for

\footnotetext{
${ }^{a}$ Institute of Electrochemical and Energy Technology,

Department of Chemical Engineering,

Shanghai Jiao Tong University, Shanghai, 200240, China.

E-mail: yangj723@sjtu.edu.cn; Fax: +86-21-5474 7667;

Tel: + 86-21-5474 7667

${ }^{b}$ Intelligent Polymer Research Institute, ARC Centre of Excellence

for Electromaterials Science, AIIM Facility, Innovation Campus,

University of Wollongong, Wollongong, NSW 2522, Australia.

E-mail: junc@uow.edu.au; Fax: +61-2-4221 3114;

Tel: +61-2-4221 3781

c ARC Centre of Excellence for Electromaterials Science,

Institute of Semiconducting and Electronic Materials, AIIM Facility,

Innovation Campus, University of Wollongong, Wollongong.

NSW 2522, Australia

† Electronic supplementary information (ESI) available: Experimental details, SEM images of the Si/MWNT mixture, Raman spectra and thermogravimetry profiles of the Si-MWNT composite and pure $\mathrm{Si}$ powder, reversible capacities of the Si-MWNT composite and $\mathrm{Si} / \mathrm{MWNT}$ mixture and schematic illustration of structural changes for different Si-CNT materials. See DOI: 10.1039/c0cc02870c
}

preparing $\mathrm{Si} / \mathrm{C}$ composite anodes. ${ }^{8,9}$ Dahn et al. appear to have been the first to prepare $\mathrm{Si} / \mathrm{C}$ composites from thermal pyrolysis of various polymers containing silicon and carbon, such as polymethylphenylsiloxane (PMPS) or polyphenylsesquisiloxane (PPSSO) in the temperature range of 900-1300 ${ }^{\circ} \mathrm{C} .{ }^{10}$ Lately, the $\mathrm{Si} @ \mathrm{C}$ composites with core/shell structure have aroused great interest because the complete carbon shell could buffer the volumetric changes of Si particles and maintain the electric contact. ${ }^{11,12} \mathrm{Ng}$ et al. reported on the synthesis of carbon-coated Si nanocomposite prepared using a spray pyrolysis method, exhibiting a capacity of $1489 \mathrm{mAh} \mathrm{g}^{-1}$ after 20 cycles. ${ }^{13} \mathrm{Hu}$ et al. prepared core/shell Si@C nanocomposites by hydrothermal treatment of a dispersion of $\mathrm{Si}$ nanoparticles and glucose in water, followed by heat treatment in nitrogen. ${ }^{14,15}$ This material presented good cycling performance with the help of vinylene carbonate (VC) electrolyte additive, but it was not stable in the conventional electrolyte without VC. Up to now, the cycling performance of core/shell $\mathrm{Si} @ \mathrm{C}$ composites is still unsatisfactory for industrial applications, perhaps due to the destruction of the carbon shell upon silicon volume variations during cycling. ${ }^{16}$ More durable composite architectures with strong adherence between silicon and carbon need to be developed to guarantee the close electric contact.

More recently, great efforts have been made toward the syntheses of nanocomposites of inorganic materials and carbon nanotubes (CNTs), ${ }^{17-19}$ with the aim of exploiting the unique properties of CNTs, such as the high aspect ratio, low mass, flexibility, high mechanical strength, and high electrical and thermal conductivities for applications in lithium ion batteries. ${ }^{20,21}$ Shu et al. demonstrated a cage-like CNTs/Si composite with a reversible capacity of $940 \mathrm{mAh} \mathrm{g}^{-1}$ and improved cycling performance for 20 cycles, where microsize $\mathrm{Si}$ particles were enwrapped by the coiled CNTs via a catalytic chemical vapor deposition (CVD) process. ${ }^{22}$ Related work was published by Kim et al., wherein the improved cyclability has been attributed to the conductive buffering role of the CNTs layer and the void space within it, which alleviated breakdown of the conductive network in Si negative electrodes. $^{23}$ However, the inhomogeneous $\mathrm{Ni}$ catalyst deposits prepared in the electroless plating process gave rise to two different types of CNTs and even caused unsuccessful growth of those in some samples. Meanwhile, the number of charge-discharge cycles was limited to only 12. Another kind of one dimensional carbon material, carbon nanofibers (CNFs), were also investigated as candidates for $\mathrm{Si} / \mathrm{C}$ composites through a CVD approach, ${ }^{24,25}$ but showed less stable cycling performance, perhaps owing to their intrinsical 


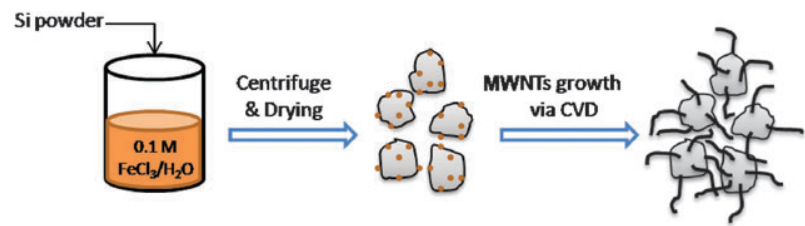

Scheme 1 Schematic procedures for the preparation of Si-MWNT composite.

deficiencies, e.g. lower mechanical strength and toughness compared to those of CNTs. ${ }^{26}$

Herein, we propose the use of a novel nanoarchitectured Si-MWNT composite as a high performance anode material, in which mutiwalled carbon nanotubes (MWNTs) were directly grown on the surface of Si nanoparticles via a simplified CVD method discarding the electroless plating procedure that is complicated and difficult to control. The obtained MWNTs are much more uniform and serve as a kind of "electronic wire" which effectively connect $\mathrm{Si}$ nanoparticles. This Si-MWNT composite shows superior cycling properties, delivering a reversible capacity of $1501 \mathrm{mAh} \mathrm{g}^{-1}$ after 20 cycles and good rate performance.

As shown in Scheme 1, in a typical experiment, Si powder with the modification of iron ion was prepared by surface adsorption technique and separated in a centrifuge at a speed of $6000 \mathrm{rpm}$. After being dried in a vacuum oven at $100{ }^{\circ} \mathrm{C}$ for half an hour, the iron modified $\mathrm{Si}$ powder was put into the furnace and was ready for the chemical vapor deposition of MWNTs. During the CVD process, the iron(III) was first reduced to iron nanoparticles under hydrogen gas flow $\left(30 \mathrm{~mL}\right.$ per $\mathrm{min}$ ) at $550{ }^{\circ} \mathrm{C}$. Then MWNTs were deposited onto Si particles at $750{ }^{\circ} \mathrm{C}$ under $\mathrm{H}_{2} / \mathrm{C}_{2} \mathrm{H}_{2} / \mathrm{Ar}(5 / 30 / 200 \mathrm{cc} / \mathrm{min})$ mix-gas flow for $20 \mathrm{~min}$. The Fe catalyst remained after the CVD process and was confirmed by EDX analysis. For comparison, the $\mathrm{Si} / \mathrm{MWNT}$ mixture was also prepared by ball milling method with the same silicon content.

Scanning and transmission electron microscopy images of the Si-MWNT composite (Fig. 1) show a successful scattered growth of MWNTs from Si particles to establish a MWNT network among $\mathrm{Si}$ particles in the sizes ranging from several
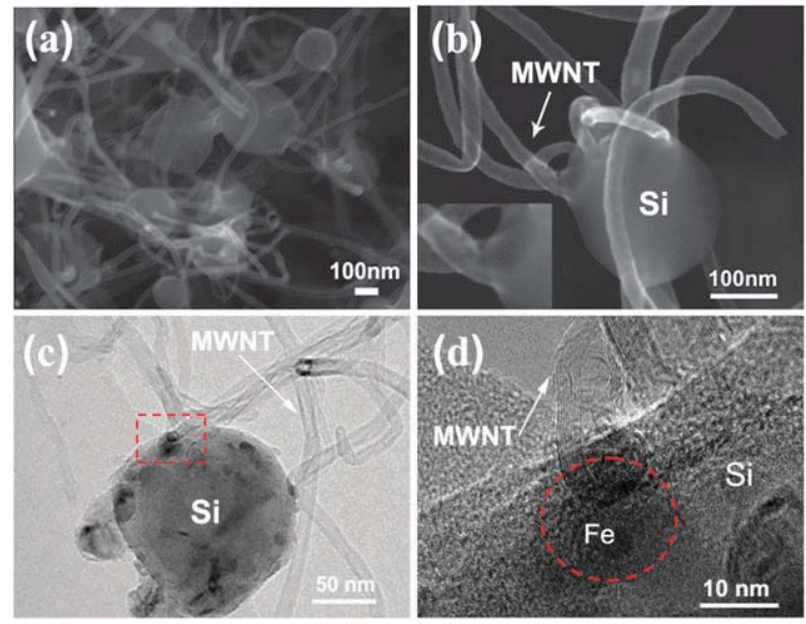

Fig. 1 SEM (a, b) and TEM (c, d) micrographs of the Si-MWNT composite (b inset, $\mathrm{c}$ and d show the Si-MWNT junctions). tens to hundreds of nanometres. The MWNTs deposited on Si have diameters of 10-30 nm (Fig. 1b and c), well matched with the $\mathrm{Si}$ particle size and comparable to the commercial MWNTs used in the Si/MWNT mixture (Fig. S1 in ESI $\dagger$ ). A clear difference can be detected between the two samples from Fig. 1 and Fig. S1 in ESI $\uparrow$. The HR-TEM micrograph of the Si-MWNT composite (Fig. 1d) demonstrates the catalytic growth of MWNTs from the surface of $\mathrm{Si}$ with strong adherence, and they have not been detached from Si particles by high power ultrasonication. This would play a key role for stability in the battery performance. For the Si/MWNT mixture, however, the Si is just entwined with MWNTs and the contact is relatively loose, as exhibited in Fig. S1b. Furthermore, the Raman spectroscopy of the Si-MWNT composite is exhibited in Fig. S2 in ESI $\dagger$, where wide D and $\mathrm{G}$ bands around 1310 and $1590 \mathrm{~cm}^{-1}$ correspond to the characteristic peaks of MWNTs. ${ }^{27}$ The content of MWNTs in the Si-MWNT composite was determined to be $31 \%$ (mass weight) via TGA analysis (Fig. S3 in ESI $\dagger$ ).

Electrochemical tests revealed a large reversible capacity of this Si-MWNT composite as high as $1592 \mathrm{mAh} \mathrm{g}^{-1}$ with an initial coulumbic efficiency of $76.9 \%$ (Fig. 2a). The capacity rose slightly for the first several cycles, which my be related to the gradual activation of $\mathrm{Si}$ host, and then stayed above $1500 \mathrm{mAh} \mathrm{g}^{-1}$ for 20 cycles. By contrast, the Si/MWNT mixture exhibited a initial capacity of only $1041 \mathrm{mAh} \mathrm{g}^{-1}$ and showed rapid capacity decay (Fig. S4 in ESI $\dagger$ ). This would be attributed to the poor electronic conductivity and resulting low utilization of active material. We also evaluated the rate performance of the Si-MWNT composite at different current densities after 40 cycles of galvanostatic charge-discharge. As shown in Fig. 2b, the composite retains about $700 \mathrm{mAh} \mathrm{g}^{-1}$ even after 80 cycles at a high current density of $500 \mathrm{~mA} \mathrm{~g}^{-1}$ and recovers to $909 \mathrm{mAh} \mathrm{g}^{-1}$ when the current density turns back. On the other hand, neither the Si/MWNT mixture nor pure Si powder can stand such high current densities.

After cycling, A.C. impedance spectroscopy of the cells was taken to study the interface property. All three electrodes exhibited Nyquist plots consisting of a depressed semicircle at high frequency range, as presented in Fig. 3, which is correlated with the electron transfer resistance on the electrode
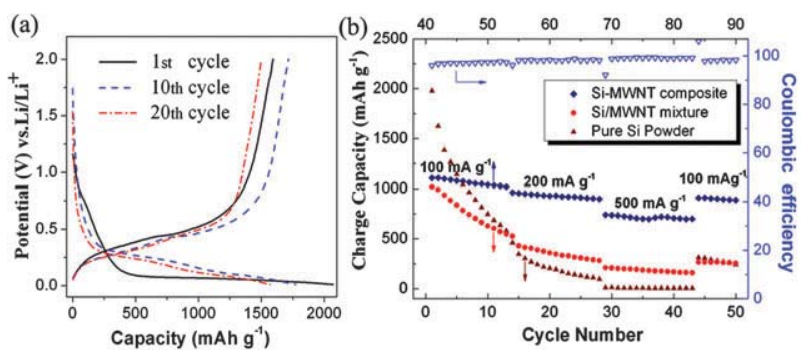

Fig. 2 (a) Galvanostatic charge-discharge profiles of the Si-MWNT composite at the 1st, 10th, and 20th cycle. (b) Rate performances of Si-MWNT composite, $\mathrm{Si} / \mathrm{MWNT}$ mixture and pure $\mathrm{Si}$ powder at different current densities from $100 \mathrm{~mA} \mathrm{~g}^{-1}$ to $500 \mathrm{~mA} \mathrm{~g}^{-1}$ and then back to $100 \mathrm{~mA} \mathrm{~g}^{-1}$. Note that the Si-MWNT composite was tested from the 41st to the 90th cycle (including the coulombic efficiency), while the $\mathrm{Si} / \mathrm{MWNT}$ mixture and pure $\mathrm{Si}$ powder from the 1st to the 50 th cycle, as indicated in the figure with different scales. 


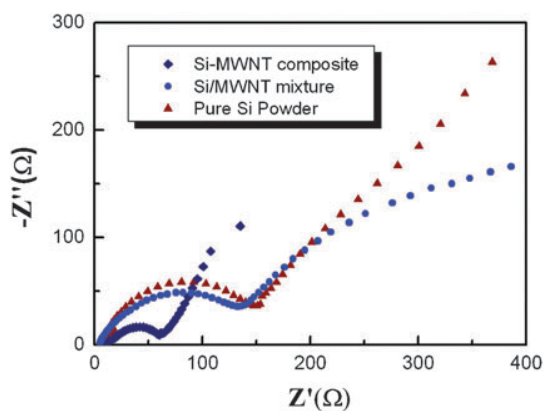

Fig. 3 Nyquist plots of the cells with Si-MWNT composite, $\mathrm{Si} / \mathrm{MWNT}$ mixture and pure Si powder electrodes after cycling.

interface. ${ }^{28}$ The Si-MWNT composite provides the smallest diameter of high frequency semicircle, indicating the good electronic contact maintained after repeated lithium insertion and extraction process, which benefits from the strong adherence and thus direct electronic connection of MWNTs on the surface of $\mathrm{Si}$ as shown in Fig. 4. By contrast, the $\mathrm{Si} / \mathrm{MWNT}$ mixture and pure silicon display larger electron transfer resistance due to the poor electronic contact during cycling. Scheme S1 in ESI $\dagger$ further illustrates the sample structures and their possible evolutions after cycling for the three kinds of Si-CNT materials. A cage-like CNT-Si composite formed by micro-sized $\mathrm{Si}$ particles and densely grown CNT (Scheme S1 A), such as reported in ref. 22, may form a thick solid electrolyte interphase (SEI) film merging the CNTs, decreasing the electronic conductivity of Si particles. In addition, coarse $\mathrm{Si}$ particles will break into smaller fragments due to the strong mechanical stress caused by the drastic volume change and result in a loss of local electronic connection. ${ }^{3}$ On the other hand, a stable conductive network between the active nanoparticles can still be maintained for the present Si-MWNT composite (Scheme S1 B), leading to excellent cycling and rate performances. However, physical mixing of MWNTs cannot prevent the breakdown of the conductive network in silicon electrodes (Scheme S1 C).

In summary, a Si-MWNT nanocomposite was successfully synthesized by direct scattered growth of MWNTs on the surface of Si nanoparticles via a CVD process using $\mathrm{C}_{2} \mathrm{H}_{2}$ as carbon source and $\mathrm{Fe}$ catalyst. This composite presents a high reversible capacity of $1592 \mathrm{mAh} \mathrm{g}^{-1}$ and good cycling stability even at large current densities of $500 \mathrm{~mA} \mathrm{~g}^{-1}$, which can be ascribed to the maintenance of a good electronic conducting network due to the robust adherence of MWNTs on Si and the
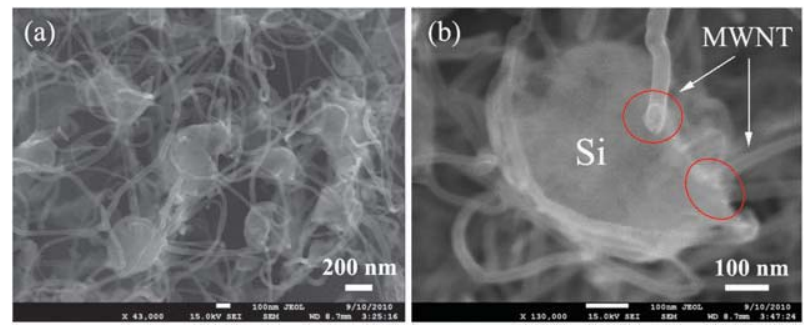

Fig. 4 SEM micrographs of a Si-MWNT composite electrode after 50 cycles. The relatively blurry particle morphology (b) may be related to the SEI film. The circled areas highlight the Si-MWNT junctions. excellent flexibility of MWNTs, which can accommodate the severe volume change of $\mathrm{Si}$ upon lithium insertion and extraction. This superior performance makes the Si-MWNT composite a promising anode material for lithium ion batteries.

We thank financial supports from the National High-tech R\&D Program (863, No.2006AA03Z232) and the National Basic Research Program (973, No.2007CB209700), China. Drs Chen and Minett would like to thank the Australian Research Council and Australian DEST Inter. Linkage Aus.-China Program for continuous financial support.

\section{Notes and references}

1 B. A. Boukamp, G. C. Lesh and R. A. Huggins, J. Electrochem. Soc., 1981, 128, 725-729.

2 S. Megahed and B. Scrosati, J. Power Sources, 1994, 51, 79-104.

3 C. K. Chan, H. Peng, G. Liu, K. McIlwrath, X. F. Zhang, R. A. Huggins and Y. Cui, Nat. Nanotechnol., 2008, 3, 31-35.

4 H. Li, X. Huang, L. Chen, Z. Wu and Y. Liang, Electrochem. Solid-State Lett., 1999, 2, 547-549.

5 M. Winter and J. O. Besenhard, Electrochim. Acta, 1999, 45, 31-50.

6 J. L. Wang and J. Yang, in Encyclopedia of Electrochemical Power Sources, ed. C. D. Juergen Garche, Patrick Moseley, Zempachi Ogumi, David Rand and Bruno Scrosati, Elsevier, Amsterdam, 2009, vol. 5, pp. 225-236.

7 W. R. Liu, J. H. Wang, H. C. Wu, D. T. Shieh, M. H. Yang and N. L. Wu, J. Electrochem. Soc., 2005, 152, A1719-A1725.

8 J. Yang, B. F. Wang, K. Wang, Y. Liu, J. Y. Xie and Z. S. Wen, Electrochem. Solid-State Lett., 2003, 6, A154-A156.

9 A. Magasinski, P. Dixon, B. Hertzberg, A. Kvit, J. Ayala and G. Yushin, Nat. Mater., 2010, 9, 353-358.

10 A. M. Wilson, J. N. Reimers, E. W. Fuller and J. R. Dahn, Solid State Ionics, 1994, 74, 249-254.

11 P. F. Gao, J. W. Fu, J. Yang, R. G. Lv, J. L. Wang, Y. N. Nuli and X. Z. Tang, Phys. Chem. Chem. Phys., 2009, 11, 11101-11105.

12 Y. Xu, G. Yin, Y. Ma, P. Zuo and X. Cheng, J. Mater. Chem., 2010, 20, 3216-3220.

13 S. H. Ng, J. Wang, D. Wexler, K. Konstantinov, Z. P. Guo and H. K. Liu, Angew. Chem., Int. Ed., 2006, 45, 6896-6899.

14 R. Demir Cakan, M. M. Titirici, M. Antonietti, G. Cui, J. Maier and Y. S. Hu, Chem. Commun., 2008, 3759-3761.

15 Y. S. Hu, R. Demir-Cakan, M. M. Titirici, J. O. Müller, R. Schlögl, M. Antonietti and J. Maier, Angew. Chem., Int. Ed., 2008, 47, 1645-1649.

16 L. W. Su, Z. Zhou and M. M. Ren, Chem. Commun., 2010, 46, 2590-2592.

17 M. S. Park, S. A. Needham, G. X. Wang, Y. M. Kang, J. S. Park, S. X. Dou and H. K. Liu, Chem. Mater., 2007, 19, 2406-2410.

18 W. Wang and P. N. Kumta, J. Power Sources, 2007, 172, 650-658.

19 H. X. Zhang, C. Feng, Y. C. Zhai, K. L. Jiang, Q. Q. Li and S. S. Fan, Adv. Mater., 2009, 21, 2299-2304.

20 J. Chen, A. I. Minett, Y. Liu, C. Lynam, P. Sherrell, C. Wang and G. G. Wallace, Adv. Mater., 2008, 20, 566-570.

21 J. Chen, J. Z. Wang, A. I. Minett, Y. Liu, C. Lynam, H. Liu and G. G. Wallace, Energy Environ. Sci., 2009, 2, 393-396.

22 J. Shu, H. Li, R. Z. Yang, Y. Shi and X. J. Huang, Electrochem. Commun., 2006, 8, 51-54.

23 T. Kim, Y. H. Mo, K. S. Nahm and S. M. Oh, J. Power Sources, 2006, 162, 1275-1281.

24 H. P. Liu, W. M. Qiao, L. Zhan and L. C. Ling, New Carbon Mater., 2009, 24, 124-130.

25 S. M. Jang, J. Miyawaki, M. Tsuji, I. Mochida and S. H. Yoon, Carbon, 2009, 47, 3383-3391.

26 J. M. Park, D. S. Kim, S. J. Kim, P. G. Kim, D. J. Yoon and K. L. DeVries, Composites, Part B, 2007, 38, 847-861.

27 P. Delhaes, M. Couzi, M. Trinquecoste, J. Dentzer, H. Hamidou and C. Vix-Guterl, Carbon, 2006, 44, 3005-3013.

28 R. Ruffo, S. S. Hong, C. K. Chan, R. A. Huggins and Y. Cui, J. Phys. Chem. C, 2009, 113, 11390-11398. 